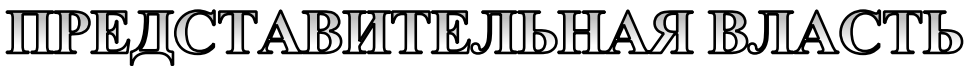

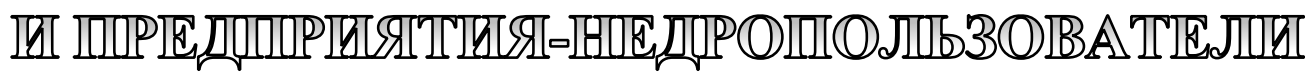

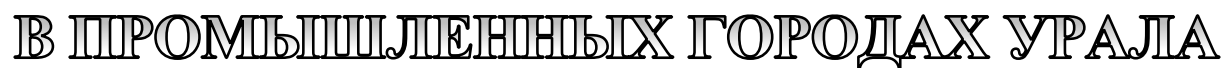

Т.Б. Витковская, Пермский федеральный исследовательский центр УрО РАН

\begin{abstract}
Статья посвящена участию недропользователей в политической жизни уральских промышленных городов. Включенность предприятийнедропользователей в городскую общественно-политическую жизнь обусловлена их тесной связью с территорией, недрами и городской инфраструктурой. Участие в деятельности органов местного самоуправления открывает недропользователям доступ к реализации политики в городе. Участие недропользователей в работе местных легислатур вовлекает их в определение вопросов, которые включаются в городскую повестку дня и в принятие общеобязательных решений, влияющих на местное сообщество и территорию.
\end{abstract}

Ключевые слова: промышленные города, недропользование, городская политика, представительный орган местного самоуправления, депутатский корпус.

В современных российских промышленных городах политические, экономические и социальные проблемы переплетаются между собой. Промышленные предприятия тесно связаны с городами, через работников и инфраструктуру, и вовлечены в городскую жизнь через социальные инициативы и политические практики. Промышленные города обладают спецификой, четко проявленной в сфере публичной политики: бизнес использует возможности политического участия, и экономический рост стимулирует политическую активность бизнеса. Определенные отраслевые сегменты местной экономики демонстрируют особенно тесную связь производства с территорией: добывающая промышленность, химическая промышленность, металлургия и др. Предприятия таких отраслей зачастую являются активными недропользователями: ведут добычу полезных ископаемых и минеральных ресурсов, используют отходы добычи и подземные воды, ведут геологическую разведку.

Статья является завершающей в цикле публикаций, посвященном политическим процессам в промышленных городах Урала (Пермский край, Свердловская и Челябинская области), в которых деятельность ведущих предприятий напрямую связана с недропользованием [1; с. 2]. В публикациях цикла предприятие-недропользователь определяется как относительно (размеров города) крупное предприятие, которое занимается добычей полезных ископаемых как сырья для промышленного производства на месторождениях, расположенных в черте города [2]. Предыдущие статьи цикла осветили проблемы взаимодействия предприятий-недропользователей и исполнительной власти в промышленных городах, участия представителей недропользователей в муниципальных выборах и конкур- 
сах на должность главы города [2], роли недропользования в формировании городского символического пространства и брендирования городов с предприятиями-недропользователями [1]. Данная статья посвящена представительству предприятий-недропользователей локальных легислатурах - представительных органах местного самоуправления, в промышленных городах.

Источником анализа послужила база данных «Политическое пространство промышленных городов Урала», которая содержит сведения о 56 промышленных городах ${ }^{1}$ Пермского края, Свердловской и Челябинской областей. База данных содержит информацию об административном статусе, структуре экономики, ведущих промышленных предприятиях, социально-экономическом положении, политической ситуации, составе органов местного самоуправления, символике городов и др. ${ }^{2}$ [3; 4, с. 151-152] Также использованы данные Сводного государственного реестра Российского федерального геологического фонда [5] и данные Центральной Избирательной комиссии Российской Федерации [6]. Анализ в данной статье носит ограниченный характер, сосредотачиваясь на одной из форм политической активности недропользователей - участию в работе представительных органов городской власти.

$$
* * *
$$

Из 56 промышленных городов, информация о которых собрана в базе данных, в 19 городах расположено в общей сложности 26 предприятий-недропользователей. Участие предприятий-недропользователей в местной политике через органы представительной власти является широко распространенной практикой: 18 из 26 недропользователей имеют своих представите- лей в городских легислатурах. Можно предположить, что если в легислатуре работает только один представитель предприятия, его избрание было его личной инициативой, а не частью тактики предприятия. Однако и после исключения предприятий с единственным представителем число недропользователей, обеспечивших себе представительство в городских легислатурах, велико - 15 из 26 предприятий. Недропользователи вовлечены в работу представительных органов самоуправления в 15 городах, и в трех из них таким образом действуют по два предприятия (Березники, Соликамск, Серов).

Предприятия-недропользователи демонстрируют интерес к органам представительной власти, потому что включение в их работу открывает новые возможности: участие в законотворческой деятельности, принятии общеобязательных решений, влияние на городскую повестку. Широкое представительство в местных легислатурах обеспечивает предприятиям прямой доступ к формированию политики в муниципалитете. Постоянное участие в деятельности представительной власти помогает недропользователям оказывать влияние на налоговую, бюджетную, промышленную политику муниципальных администраций, защищать собственные финансовые и имущественные интересы, формировать по возможности, более благоприятные условия для производственной деятельности, то есть достаточно эффективно лоббировать интересы бизнеса в органах публичной власти. Несколько депутатов, аффилированных с предприятием, предоставляют возможность влияния на работу легислатуры, тогда как депутатская группа, определяющая результаты голосования, гарантирует контроль над ней. Доля депутатов, аффилированных с мест-

\footnotetext{
${ }^{1}$ Города отнесены к промышленным по структуре занятости населения: доля работников предприятий добывающей и обрабатываюшей промышленности составляет не менее $20 \%$ занятого населения [3].

${ }^{2}$ База данных создана в 2017-2019 гг. сотрудниками отдела по исследованию политических институтов и процессов Пермского федерального исследовательского центра под руководством проф. П.В. Панова в рамках комплексной программы фундаментальных исследований УрО РАН.
} 
ными недропользователями, составляет почти половину от общего числа депутатов в городах Магнитогорск, Кировград, Красноуральск, Соликамск и Серов.

Политическая ситуация в Магнитогорске, втором по величине городе Челябинской области, - пример того, как в крупном городе предприятие, тесно связанное с ним, может обрести и удерживать контроль над органами власти. Магнитогорский металлургический комбинат является одним из крупнейших в России и располагает всеми необходимыми для «захвата» органов местного самоуправления ресурсами: от финансовых средств до лоббистов, действующих на региональном и федеральном уровнях. В настоящее время бывшие работники металлургического производства занимают лидерские позиции в органах городской власти: глава города был начальником управления капитального строительства на Магнитогорском металлургическом комбинате, председатель городского Собрания депутатов мастером на Магнитогорском метизнометаллургическом заводе. Комбинат контролирует локальную исполнительную власть - через главу города, и представительную власть - через депутатскую группу, составляющую почти половину депутатского корпуса (14 из 32 депутатов) [2].

В небольших городах недропользователь может приобретать политическое влияние с меньшими усилиями, поскольку круг влиятельных местных акторов очень ограничен и региональная власть, как правило, не вмешивается в местную политику. Так, в Кировграде медеплавильный завод - Кировградская металлургическая компания, имеет большинство в окружной Думе (16 из 20 депутатов аффилированы с предприятием), в Красноуральске медеплавильному комбинату «Святогор» не хватает одного представителя для простого большинства в окружной Думе (7 из 15 депутатов аффилированы с предприятием). В обеих территориях окружные гла- вы также представляют предприятия. В Соликамске и Серове предприятия-недропользователи обеспечили себе представительство, но не большинство, в городских Думах. В Серове Надеждинский металлургический завод имеет на одного депутата меньше, чем требуется для простого большинства (12 из 25 депутатов представляют завод), в Соликамске «Уралкалий» имеет на одного депутата меньше, чем необходимо для получения трети голосов (8 из 25 депутатов работают на заводе). Это связано c конкуренцией за представительство в органах местного самоуправления: в обоих городах в легислатурах работают и представители других предприятий. «Уралкалий» сталкивается с конкуренцией за депутатские мандаты и в городе Березники, где находятся не только его производственные мощности, но и штабквартира. В Березниковской Думе есть депутатские группы от трех предприятий, и группа «Уралкалия» составляет четверть от общего числа депутатов.

Недропользователи конкурируют за влияние на представительную власть и друг с другом, если работают на одной территории. Даже не являясь конкурентами в бизнесе, они могут активно конкурировать в политическом пространстве, соперничая за преимущественное влияние на городскую власть. Так, в Серове завод ферросплавов заинтересован в представительстве в легислатуре не менее, чем металлургический завод. С «Уралкалием» за политическое представительство в Соликамске конкурирует предприятие «Соликамскбумпром», в Березниках - металлургическая компания «Ависма».

Представлены в локальных легислатурах малыми группами (от двух до пяти депутатов) следующие недропользователи: «Горноблагодатское Рудоуправление» в Кушве, «Среднеуральский медеплавильный завод» в Ревде, «Сухоложский огнеупорный завод» в Сухом Логу, «Богословский алюминиевый завод» в Краснотурь- 
инске, «Огнеупоры» в Богдановиче и «Карабашмедь» в Карабаше (табл.). Отдельные предприятия их числа тех, что ведут работу с недрами и привязаны к территории расположения производства, отказываются от присутствия в местных легислатурах. Но отказ от политического представительства не происходит повсеместно. В четырех промышленных городах из 19 недропользователи (или единственный недропользователь) не участвуют в работе городской представительной власти. Восемь предприятий-недропользователей из 26 не имеют представителей в органах местного самоуправления.

В одних случаях предприятия не имеют доступа к нормотворческому процессу, к формированию политики в городе, поскольку проиграли в соперничестве другому предприятию, более активному или обеспеченному ресурсами. В других случаях они не имеют

Таблицุа

Представительство предприятий-недропользователей в городских легислатурах; третья колонка - число депутатов, аффилированных с предприятием-недропользователем (первая цифра) и численность депутатского корпуса (вторая цифра, в скобках).

Таблица составлена на основе данных Сводного государственного реестра Российского федерального геологического фонда [5] и Базы данных «Политическое пространство промышленных городов Урала» [3].

\begin{tabular}{|c|c|c|}
\hline Город,субъект РФ & Предприятие - недропользователь & Число депутатов \\
\hline $\begin{array}{c}\text { Соликамск, } \\
\text { Пермский край }\end{array}$ & «Уралкалий», ПАО & $8(25)$ \\
\hline $\begin{array}{c}\text { Соликамск, } \\
\text { Пермский край }\end{array}$ & «Соликамскбумпром», АО & $3(25)$ \\
\hline $\begin{array}{c}\text { Березники, } \\
\text { Пермский край }\end{array}$ & «Уралкалий», ПАО & $6(25)$ \\
\hline $\begin{array}{c}\text { Березники, } \\
\text { Пермский край }\end{array}$ & «Ависма», ПАО & $3(25)$ \\
\hline $\begin{array}{c}\text { Кировград, } \\
\text { Свердловская область } \\
\end{array}$ & $\begin{array}{l}\text { «Производство } \\
\text { полиметаллов» }\end{array}$ & $16(20)$ \\
\hline $\begin{array}{c}\text { Кушва, } \\
\text { Свердловская область }\end{array}$ & $\begin{array}{c}\text { «Горноблагодатское } \\
\text { рудоуправление» }\end{array}$ & $2(20)$ \\
\hline $\begin{array}{c}\text { Ревда, } \\
\text { Свердловская область }\end{array}$ & $\begin{array}{c}\text { «Реднеуральский медеплавильный } \\
\text { завод», ПАО }\end{array}$ & $5(20)$ \\
\hline $\begin{array}{c}\text { Сухой Лог, } \\
\text { Свердловская область }\end{array}$ & $\begin{array}{c}\text { «Сухоложский огнеупорный } \\
\text { завод», ОАО }\end{array}$ & $2(20)$ \\
\hline $\begin{array}{c}\text { Красноуральск, } \\
\text { Свердловская область }\end{array}$ & «Святогор», ОАО & $7(15)$ \\
\hline $\begin{array}{c}\text { Краснотурьинск, } \\
\text { Свердловская область }\end{array}$ & $\begin{array}{c}\text { «Богословский алюминиевый } \\
\text { завод», ОАО }\end{array}$ & $3(20)$ \\
\hline $\begin{array}{c}\text { Серов, } \\
\text { Свердловская область }\end{array}$ & $\begin{array}{c}\text { «Надеждинский металлургический } \\
\text { завод», ПАО }\end{array}$ & $12(25)$ \\
\hline $\begin{array}{c}\text { Серов, } \\
\text { Свердловская область }\end{array}$ & $\begin{array}{l}\text { «Серовский завод } \\
\text { ферросплавов», АО }\end{array}$ & $2(25)$ \\
\hline $\begin{array}{c}\text { Богданович, } \\
\text { Свердловская область }\end{array}$ & $\begin{array}{l}\text { «Богдановичское по производству } \\
\text { огнеупорных материалов», ОАО }\end{array}$ & $5(20)$ \\
\hline $\begin{array}{c}\text { Сатка, } \\
\text { Челябинская область }\end{array}$ & «Магнезит», ОАО & $1(21)$ \\
\hline $\begin{array}{c}\text { Магнитогорск, } \\
\text { Челябинская область }\end{array}$ & $\begin{array}{c}\text { «Магнитогорский } \\
\text { металлургический комбинат», ПАО }\end{array}$ & $14(32)$ \\
\hline Карабаш, Челябинская область & Карабашмедь, АО & $2(15)$ \\
\hline $\begin{array}{c}\text { Верхнеуральск, } \\
\text { Челябинская область }\end{array}$ & $\begin{array}{c}\text { «Учалинский горно-обогатительный } \\
\text { комбинат», АО }\end{array}$ & $1(15)$ \\
\hline $\begin{array}{c}\text { Карталы, } \\
\text { Челябинская область }\end{array}$ & «Риср-Микромрамор», ООО & $1(31)$ \\
\hline
\end{tabular}


лоббистского или иного интереса

в отношении органов местной власти

и по этой причине не принимают участия в муниципальных выборах.

В Соликамске два недропользователя «Соликамский магниевый завод» и завод «Урал», не представлены в городской Думе, где почти половину мест занимают представители других, более крупных предприятий-недропользователей. В Краснотурьинске градообразующее предприятие, недропользователь «Богословское рудоуправление», не имеет мандатов в Думе округа, которые при необходимости мог бы обеспечить холдинг «Уральская горнометаллургическая компания», в состав которого входит предприятие. Один сотрудник, взрывник рудоуправления, принял участие в выборах депутатов, вероятно, по личной инициативе, и не получил мандат [7]. Должности в органах городской власти занимают представители другого местного недропользователя, «Богословский алюминиевый завод» в составе корпорации «Русал»: глава города до избрания работал на заводе, и несколько депутатов Думы - работники завода. В Горнозаводске и Катавск-Ивановске в представительных органах местного самоуправления нет представителей промышленных предприятий, недропользователи «Горнозаводскцемент» и «Катавский цемент» не проявляют интереса к городской политике.

Кроме того, в отдельных случаях отказ от политической активности является следствием финансовых или организационных трудностей, с которыми столкнулось предприятие. Так, в настоящее время «Уфалейникель» в Верхнем Уфалее отказался от участия в политической жизни в связи с финансовыми проблемами, хотя раньше имел прямой доступ к формированию политики в городе через окружное Собрание депутатов [8].

$$
* * *
$$

Предприятия могут участвовать в политике различными способами. Промыш- ленные предприятия, которые тесно связаны с территорией, на которой расположены и используют местные недра и городскую инфраструктуру, как правило, участвуют в политике через своих представителей в органах публичной власти - городских глав, муниципальных депутатов. Они финансируют и организационно поддерживают избирательные кампании собственных кандидатов. На поддержку кандидатов работает значимость градообразующего или крупного предприятия, недропользователя, для города как работодателя, налогоплательщика и благотворителя. В промышленных городах, где производство тесно связано с городом, участие заводчан в работе органов власти соответствует ожиданиям большинства горожан.

Избрание работников промышленных предприятий в органы представительной власти - распространенная практика в промышленных городах с предприятиями-недропользователями. Как правило, предприятия представлены в городских легислатурах не одним кандидатом, а группой, которая может составлять до половины состава депутатского корпуса. Конкуренция предприятий за депутатские мандаты, обеспечивающие представительство, осложняет доступ в органы публичной власти. Принадлежность недропользователя к крупной корпорации означает обеспеченность финансовыми и другими ресурсами, необходимыми для ведения политической деятельности, но на городском уровне могут быть политически активны и местные недропользователи. Представители предприятия в депутатских собраниях участвуют в формировании повестки, законотворческой деятельности, согласовании значимых для территории и сообщества решений. Таким образом, предприятия-недропользователи получают доступ к формированию и реализации политики в городе и становятся полноправными участниками политического процесса.

\section{Библиографический список}

1. Кирьянов И.К., Назукина М.В. Символика недропользования в современной геральдике и брендинге уральских городов // Вестник Пермского федерального исследовательского центра. - 2020. - № 2. - С. 76-88. 
2. Ковин В.С., Панов П.В., Петрова Р.И. Предприятия-недропользователи и конкурсы по выборам главы города // Вестник Пермского федерального исследовательского центра. -2020 . - № 3 .

3. Панов П.В. База данных «Политическое пространство промышленных городов Урала» // Вестник Пермского научного центра. - 2018. - № 3. - С. 77-82.

4. Панов П.В. Политическое пространство промышленных городов Урала // Современный город: власть, управление, экономика. Современный город как объект публичного управления. - 2019. Вып. IX. - С. 149-156.

5. Сводный государственный реестр Российского федерального геологического фонда [Электронный pecypc] - URL: https://www.rfgf.ru/license/index.php (дата обращения: 09.08.2020).

6. Сведения о кандидатах. Данные о итогах голосования по одномандатным (многомандатным) округам. Официальный сайт Центральной избирательной комиссии Российской Федерации. Информация о выборах и референдумах [Электронный ресурc] - URL: http://www.vybory.izbirkom.ru/ (дата обращения: 09.08.2020).

7. Сведения о кандидатах, выдвинутых по одномандатным (многомандатным) избирательным округам. Выборы депутатов Думы городского округа Краснотурьинск седьмого созыва. Краснотурьинская городская территориальная избирательная комиссия. Официальный сайт Центральной избирательной комиссии Российской Федерации. Информация о выборах и референдумах [Электронный ресурс] URL: http://www.sverdlovsk.vybory.izbirkom.ru/region/region/sverdlovsk (дата обращения: 09.08.2020).

8. «Уфалейникель» окончательно ликвидируют. 18 марта 2019 г. Новости Верхнего Уфалея [Электронный pecypc] - URL: http://ufaleyka.ru/news/society/ufaleynikel-final-disposition/ (дата обращения: 09.08.2020).

\title{
REPRESENTATIVE PUBLIC AUTHORITIES AND SUBSURFACE USERS ENTERPRISES IN THE INDUSTRIAL CITIES OF THE URAL REGION
}

\author{
T.B.Vitkovskaya \\ Perm Federal Research Center UB RAS
}

This paper looks into the participation of enterprises - subsurface users in the political life of the Ural industrial cities. The involvement of enterprises - subsoil users in the urban social and political life is due to their close connection with the territory, subsoil and urban infrastructure. Participation in the activities of local government bodies gives subsurface users the access to policy implementation in the city. Participation of subsurface users in the work of local legislatures involves them in defining issues that are included in the city agenda and in decision-making process that affects the local community and territory.

Keywords: industrial cities, subsurface use, urban politics, representative body of local government, deputy corps.

\section{Сведения об авторе}

Витковская Татьяна Борисовна, кандидат политических наук, научный сотрудник отдела по исследованию политических институтов и процессов, Пермский федеральный исследовательский центр УрО РАН (ПФИЦ УрО РАН), 614900, г. Пермь, ул. Ленина, 13А; e-mail:vit.tatiana@gmail.com 